\title{
LABOR EDUCATIVA CON LOS JÓVENES. UN RETO DE LAS UNIVERSIDADES EN EL SIGLO XXI
}

Ph.D. Juana María Cubela González. Docente Titular

Universidad de Oriente, Cuba

jmcubela@uo.edu.cu

Palabras claves: labor educativa, enfoque humanista, preventivo, personológico y desarrollador del estudiante

Recibido: 10de octubre de 2016

Keywords: educational work, humanistic , preventive,personological Aceptado: 26 de noviembre de 2016 approach

\section{RESUMEN}

En el presente trabajo se fundamenta la labor educativa que ha de realizarse con los jóvenes, los cambios que han de producirse en las maneras de concebir y hacer esta labor y de las nuevas actitudes que deben adoptar los docentes que posibiliten la adaptación a los nuevos roles que les corresponden ejercer. En tal sentido, se pretende como objetivo promover la reflexión y autorreflexión de los docentes sobre cómo llevar a cabo esta labor atendiendo a las características de los estudiantes y a las nuevas condiciones socio - históricas que les ha tocado vivir, desde un enfoque humanista, preventivo, personológico y desarrollador.

\section{ABSTRACT}

The present article deals with the educational work to be done with young people, the changes that might occur in the ways of conceiving and doing this work and the new attitudes that teachers should adopt to enable them to adapt to the new roles. In this sense, the objective is to promote reflection and self - reflection of teachers on how to carry out this work taking into account the characteristics of the students and the new socio - historical conditions that they have had to live, through a humanístic , personological and preventive approach that promotes development. 


\section{INTRODUCCIÓN}

En la universidad del siglo XXI la labor educativa debe convertirse en la piedra angular en la formación inicial del profesional, se parte de la premisa de que el joven de hoy ha cambiado su manera de ser, hacer, sentir, convivir y aprender. De la misma manera los padres y los profesores han cambiado también. Unos y otros son exponentes de una nueva época con nuevas y complejas necesidades, problemáticas y características socioeducativas que no tiene nada que ver con años vividos en el siglo XIX y XX.

La autora valora que los resultados académicos, la retención, la actitud ante el estudio, las relaciones de convivencia son el resultado, más que de la instrucción recibida, de la labor educativa realizada por estudiantes y profesores. No se trata solamente de asignar más presupuestos, más computadoras, más aulas, lo cual es importante, pero no lo que determina la formación integral de una personalidad sana, equilibrada, autónoma y culta. Se necesita de una labor educativa más a tono con las características socio-física - psicológicas y personológicas de los estudiantes actuales, que más que una acumulación de teorías y de técnicas para ser enseñados necesitan de formas personalizadas de hacer por su educación para ayudarlos humana y profesionalmente a amar y desear una supervivencia compensada.

Con este trabajo se pretende como objetivo promover la reflexión y autorreflexión de los docentes sobre cómo llevar a cabo la labor educativa atendiendo a de las características de sus estudiantes y las nuevas condiciones socio - históricas que les ha tocado vivir, desde un enfoque humanista, preventivo, personológico y desarrollador.

\section{DESARROLLO}

La labor educativa, es considerada por la autora, como el quehacer pedagógico del profesor en interrelación e interacción activa con los estudiantes para promover de manera intencionada, sistemática, sistémica y coherente el proceso formativo para el desarrollo de conocimientos, sentimientos, valores, cualidades, convivencias y modos de comportamientos que sean personalmente significativos para los estudiantes acorde con los objetivos de su modelo de formación en correspondencia con sus características socio-física psicológicas - personológicas y la situación socio histórica y contextual que les ha tocado vivir.

La complejidad de la labor educativa radica precisamente en que el proceso formativo de los estudiantes no se reduce tan sólo a la asimilación de los contenidos de las diferentes asignaturas, de las representaciones morales y de diferentes hábitos y habilidades de comportamiento, sino que la misma tiene que vincularse a las necesidades vitales de los estudiantes, sus características personales y de los contextos en los que se desarrolla y se transforma. Existen determinadas exigencias que deben tenerse en cuenta:

- La labor educativa demanda de intencionalidad en la planificación, organización y aseguramiento de las acciones a desarrollar sistemáticamente.

- Ha de lograrse motivación, entusiasmo y el compromiso de todos, principalmente del estudiante, con las actividades y acciones educativas a desarrollar. 
- Se requiere de la asunción o asignación de responsabilidades individuales, compartidas y colectivas.

- Es conveniente la promoción del liderazgo compartido, ya sea formal o informal de todos y cada uno de los jóvenes atendiendo a sus potencialidades, cualidades o aptitudes.

- Es imprescindible la coherencia, unidad, influencia, coordinación y la colaboración sostenida de los principales gestores y actores en la orientación y ejecución de las acciones educativas convenidas.

Una adecuada labor educativa se hace tangible en los impactos que se logran a partir de los resultados obtenidos en indicadores tales:

- Activismo, participación, protagonismo estudiantil en las diferentes actividades, acciones o tareas de aprendizaje y socioeducativas que se desarrollan en la institución escolar.

- Creatividad y entusiasmo durante la planificación, organización, ejecución, control y evaluación de las actividades académicas, científicas, laborales, extensionistas.

- Comportamiento de los indicadores de eficiencia en los últimos 5 cursos (asistencia, retención y promoción). Eficiencia en el ciclo.

- Resultados en la realización de los tareas o ejercicios integradores.

- Calidad y cantidad de estudiantes en la realización de exámenes de premio, mejora de notas y con título de oro.

- Calidad en la realización del trabajo científico estudiantil.

- Participación y resultados obtenidos por los estudiantes en eventos, fórums, concursos, festivales.

- Cantidad de premios y avales obtenidos.

Alcanzar resultados positivos e impactos en la labor educativa que se realiza con los jóvenes actualmente significa cambiar la visión que se tiene de este proceso y enrumbarlo de manera diferente, a criterio de la autora, desde un enfoque humanista, preventivo, personológico y desarrollador del estudiante que se forma en nuestras aulas y en los diferentes escenarios formativos.

La labor educativa con un enfoque humanista requiere dar intencionalidad a lo que se hace educativamente para dar tratamiento, atención u orientación al estudiante con la comprensión de que es un ser humano que nunca va a ser perfecto pero si perfectible a pesar de sus errores, dificultades, defectos, desviaciones, faltas, privaciones, insuficiencias y fallas. Tener la convicción profesional de que se pueden desarrollar los sentimientos, cualidades, valores, modos de comportamientos y normas de conducta más nobles y genuinos en cada estudiante, con la utilización de métodos, procedimientos y estrategias humanistas 
que permitan que accedan de manera reflexiva y crítica al conocimiento de lo que necesitan para ser humanamente mejor para sí y para los demás. Es tratar afectivamente al estudiante como se quisiera que se tratara a uno mismo.

El enfoque preventivo debe tener como principio la atención del universo de estudiantes independientemente de que estos evidencien o no situaciones que en el orden personal, familiar, social o institucional puedan llevarlos a presentar factores de riesgos, ya sean de carácter afectivo y/o materiales, o que puedan poner en peligro el desarrollo adecuado de la personalidad. Significa anticiparse o adelantarse al tratamiento a las drogas, la salud física y mental, los conflictos personales, las manifestaciones de violencia, la sexualidad irresponsable, la no calidad del aprendizaje antes de que se aprecien tangiblemente en el contexto universitario.

Se ha de estimular la reflexión y la autoreflexión del estudiantado de las consecuencias que traen consigo las manifestaciones negativas antes señaladas, de qué puede hacer y cómo para evitar esos comportamientos y asumir actitudes positivas ante los problemas de la vida, independientemente de los obstáculos que puedan sobrevenir en cualquier medio o contexto por adverso que sea.

El enfoque personológico implica centrarse en cada joven con personalidad única e irrepetible, orientándolos educativamente en la potenciación de sus recursos personales y personológicos para enfrentar por sí mismo situaciones adversas y la construcción de proyectos de vida y profesionales sobre la base de sus experiencias, vivencias, errores y dificultades con una visión optimista del futuro, utilizando y desarrollando los autorreferentes y otras formaciones psicológicas en el autoperfeccionamiento de su personalidad.

Por ejemplo, la autovaloración, autoconocimento, autoconfianza, autoestima, autodeterminación, así como formaciones psicológicas tan importantes como los ideales, intenciones, convicciones u otras, en la interrelación dialéctica de los procesos sociales e intrapsíquicos que posibilitan tener una personalidad cada vez más recobrada independientemente de las reveses del medio.

Lo anterior debe entenderse como un proceso en espiral donde las distintas etapas de la formación de la personalidad se van fortaleciendo en los logros de la siguiente, a través de la maduración psicológica que se pone de manifiesto en: el desarrollo progresivo de la autorregulación; el control de emociones e impulsos; el manejo positivo de los problemas y conflictos en pos de soluciones viables; la activación de un pensamiento crítico que conlleve a la toma de decisiones y al alcance de nuevas metas, propósitos, aspiraciones; y la contribución personal en la creación de un ambiente de tolerancia, aceptación y respeto en las relaciones de convivencia.

Enseñar y entrenar al joven a estructurar y desarrollar gradualmente su propio proyecto de vida significa anticiparse, modelar e imaginar cómo representar el ideal de su propia vida de manera realista y equilibrada, en consonancia con sus potencialidades y necesidades personales y contextuales e irlas revelando en la cotidianidad de su coexistencia. Tiene que ser capaz de tener perspectiva de vida, definir sus misiones, trazarse metas, planes inmediatos o a corto, mediano y largo plazo, tomar conciencia de la responsabilidad que debe tener para alcanzarlos y qué puede reprogramar oportunamente para lograr lo que se ha propuesto. 
El enfoque desarrollador concibe la labor educativa como estimuladora en el estudiante de la reflexión - autorreflexión profunda, la participación e implicación activa y protagónica en los cambios cualitativos que han de producirse en sus formas de conocer, ser, hacer, comportarse, convivir con autonomía, autodeterminación, compromiso y responsabilidad para ir logrando el autoperfeccionamiento sostenido de su personalidad. Para ello, se hace ineludible la formación del sí mismo que permite integrar el desarrollo afectivo - motivacional - valorativo y cognitivo - instrumental, la capacidad para asumir el enfrentamiento positivo de problemas para facilitar la transformación y el desarrollo personal-social.

El enfoque que se presenta de la labor educativa con los estudiantes resulta procedente ya que se está formado una juventud que se caracteriza por una psicología basada en la manifestación de sus sentimientos, aprendizajes, proyectos propios y no en su contención, porque sería imposible llegar al raciocinio y al corazón de los jóvenes al margen de las rasgos caracterológicos que los distinguen actualmente y de las nuevas condiciones socio - históricas que les ha tocado vivir y si no se utilizan los métodos, procedimientos y estrategias educativas que respondan a su verdadera naturaleza humana.

Es ineludible, entonces, enfatizar en la importancia que representa para la labor educativa del educador tener como premisa la adecuada caracterización y el diagnóstico integral, optimista, sistemático, colaborativo, multi e interdisciplinario, pronosticador, preventivo, dinámico, multifactorial, ecológico y transformador del estudiante y su grupo.

A continuación se expondrán algunos rasgos caracterológicos de los jóvenes actuales, a partir de la profundización en múltiples investigaciones que se han realizado mundial y nacionalmente, sin que conlleve a clasificar, encasillar, etiquetar a los estudiantes, sino familiarizarnos con sus maneras de ser, aprender y proyectarse, a fin de esclarecer y actualizar los procesos de desarrollo humano integral que necesitan, y así poder realizar una labor educativa coherente y desarrolladora.

- Los jóvenes actuales son capaces de comprender y experimentar los sentimientos, pensamientos y experiencias de otros, sin necesidad de expresarse verbalmente.

- Saben manejar fácilmente los instrumentos electrónicos y computadoras, con acceso al conocimiento de manera inmediata a través de un bombardeo de informaciones diversas que se complementan a través de diferentes medios de comunicación.

- Prefieren más estudiar autodidácticamente, investigar, utilizar los avances de la tecnología de punta, a estar obligado a atender clases monótonas y a veces poco interesantes, con profesores que se manifiesten de manera rígida y conservadora.

- Se aburren simplemente porque son veloces y requieren de materias interesantes y de métodos de enseñanza motivadores y productivos.

- Les resulta frustrante cualquier sistema de estudio que requiera muy poca creatividad o que no les dé la libertad de aprender lo que necesitan.

- Poseen una visión distinta de la vida y un rechazo a las tareas rutinarias. 
- Se resisten a la autoridad si no es democráticamente orientada.

- Su capacidad crítica un tanto mordaz y su descontento con el sistema educativo y los adultos que no les comprenden, los atacan, o minimizan.

- Algunos manifiestan, con decepción, que están descontentos con la forma de ser de algunos de sus profesores, padres y que desearían mayor ayuda y comunicación de su parte.

- Tienen un potencial extraordinario para los aprendizajes de vida y académicos, los proyectos de aprendizaje pero a veces se estimula y se aprovecha poco.

- Muestran una insaciable curiosidad, les gusta la investigación y aprender cosas novedosas e inusuales, poseen mucha imaginación y creatividad.

- Son íntegros y congruentes entre sus pensamientos, sentimientos, palabras y acciones.

- Tienen un nivel energético elevado y muy sano, presentando un metabolismo acelerado.

- Son sensibles al dolor ajeno, sumamente compasivos con un alto grado de em patía, pero no son susceptibles al chantaje o manipulación emocional ni a la sensiblería.

- Suelen amar la naturaleza, el medio ambiente.

- Oscilan entre una muy alta autoestima y fuertes bajones (a veces, con serios casos de depresión).

- Demuestran una alta autonomía desde las edades más tempranas.

- Pueden hacer dos o tres actividades a la vez.

- Hacen valoraciones profundas y críticas sobre sus profesores y padres. No soportan la mentira, el engaño, la manipulación (aunque algunos jóvenes han aprendido a manipular como medio de defensa y a utilizar las mismas herramientas que utilizan con ellos los adultos).

- No soportan los sermones, chantajes, ni a alguien que les alce la voz.

- Pueden ser menos robustos físicamente y más vulnerables emocionalmente.

- No entienden la inhumanidad del hombre hacia el hombre, la guerra, la avaricia, etc., pueden sentirse fácilmente abrumados por todo eso.

Estas manifestaciones son en gran medida resultado de importantes causales que han de tenerse en cuenta para educar consecuentemente:

- La sociedad se ha ido tecnologizando y sofisticando vertiginosamente. 
- La extrema velocidad de los cambios de la naturaleza.

- Los padres y docentes muchas veces no tienen la oportunidad de un contacto permanente con los jóvenes por el exceso de trabajo, de responsabilidades,los problemas y conflictos que tienen que solucionar.

- A veces se educa para la repetición, se premia la memoria y el automatismo, se condena a los estudiantes a perder rápidamente su motivación y se califica para que sólo aprendan a reproducir modelos ajenos.

- A veces se centra la formación en el desarrollo del conocimiento (que no es igual a sabiduría), al desarrollo de la inteligencia (que no es igual a la mente); más aún, se ha olvidado de la educación de la afectividad, sin tener presente que el ser humano es cuerpo, conocimiento y afecto integradamente.

Ante estas manifestaciones y causales la labor educativa ha de basarse permanentemente en el diálogo ameno, las relaciones asertivas, la escucha atenta en un proceso de diseño y hacer colectivo que potencie la individualidad y el respeto a la diversidad, utilizando métodos y procedimientos que apunten a la creación de proyectos que inciten a la autogestión: de vida, profesionales, educativos, de aprendizaje, de investigación, elaboración de productos tecnológicos: software, multimedia, libros electrónicos, powerpoint, la orientación adecuada para la utilización de las redes sociales con fines académicos y aulas virtuales, la utilización de terapias de aprendizaje: musicoterapia, riso terapia, canto terapia, jardín terapia, ejercicios de relación y anti stress, de meditación, relajación muscular, de respiración, la investigación acción - hallazgo sobre la cultura y otras culturas, la relación entre medio ambiente - educación - ser humano, estimulado el contacto directo con la naturaleza u otras.

\section{CONCLUSIONES}

La labor educativa se convierte hoy más que nunca en la piedra angular de la formación inicial, en particular en la formación profesional de las universidades, exigiendo actualmente de cambios en la manera de ver, comprender, tratar, atender u orientar educativamente a los estudiantes, desde un nuevo enfoque humanista, preventivo, personológico y desarrollador.

En esta labor educativa que se fundamenta es consustancial prestar atención a la máxima educativa de que cada joven es único y especial por sí mismo, pero considerando las manifestaciones caracterológicas que tienden a prevaler en ellos en el presente siglo, por la gran responsabilidad que se tiene de educarlos para sí, para la sociedad y para poder garantizar la supervivencia de la humanidad. 


\section{REFERENCIAS BIBLIOGRÁFICAS}

Cubela , JM. (2015). Los proyectos educativos de año y grupo potenciadores de la labor educativa en las UCP. Material docente de la DFP (Dirección de Formación del Profesional (DFP) de la Universidad de Oriente (UO). Santiago de Cuba.

Delors, J(1996) . La educación encierra un tesoro. Informe a la UNESCO de la Comisión Internacional sobre la Educación del siglo XXI. Ed. UNESCO.Francia.

Horruitiner , P. (2000) La labor educativa desde la dimensión curricular. Pedagogía Universitaria. Vol. 5 No. 1.

Paymal, N. Pedagogía 3000.Recuperdao de www.pedagogia3000.info.2014. 